\section{Sensorineural hearing loss in high school teenagers in Mexico City and its relationship with recreational noise}

\author{
Las alteraciones auditivas de escolares \\ adolescentes en la Ciudad de México \\ pueden estar relacionadas al ruido \\ recreativo
}

María del Consuelo Martínez-Wbaldo 1

Claudia Soto-Vázquez ${ }^{1}$

Ivonne Ferre-Calacich 1

Elizabeth Zambrano-Sánchez 1

Lucía Noguez-Trejo 1

Adrián Poblano ${ }^{2}$

\author{
1 Departamento de \\ Epidemiología, Instituto \\ Nacional de Rehabilitación, \\ Ciudad de México, México. \\ 2 Laboratorio de \\ Neurofisiología Cognoscitiva, \\ Instituto Nacional de \\ Rehabilitación, Ciudad de \\ México, México. \\ Correspondence \\ A. Poblano \\ Laboratorio de \\ Neurofisiología Cognoscitiva \\ Instituto Nacional de \\ Rehabilitación. \\ Av. México-Xochimilco 289, \\ Col. Arenal de Guadalupe, \\ Deleg. Tlalpan, 14389, \\ México DF, México. \\ drdeaf@latinmail.com
}

\begin{abstract}
The aim of this study was to measure the frequency of hearing loss in a sample of typical public highschool students exposed to recreational noise, and determine associated risk factors. The sample was made up of 214 teenagers from a high-school in Mexico City; subjects were selected randomly per strata. We applied a questionnaire to identify risk factors for hearing loss and performed a battery of audiologic tests consisting of otoscopy, tympanometry, and pure-tone audiometry. The mean age of the sample was $16 \pm 1.07$ years; $73 \%$ were male and $27 \%$, female. Hearing loss was found in $21 \%$ of students. The main hearing loss-related risk factor was exposure to recreational noise: frequent attendance at discotheques and popmusic concerts; use of personal stereos; and noise exposure in school workshops. The high frequency of hearing loss in high school students from one Mexico City school (nearly one fifth of the sample) was found to be related to noise exposure mainly during recreational activities.
\end{abstract}

Hearing Loss; Noise Effects; Acoustic Trauma; Adolescent

\section{Introduction}

Sensorineural hearing loss prevalence in developing countries has been studied very little across different age groups. Different conclusions are drawn for each population studied depending on their socio-economic and geographic characteristics. In a country such as Mexico, sensorineural hearing loss may be more frequent among populations living in poverty. For example, in a recent study performed in otherwise healthy newborns from a private hospital in one of the wealthiest counties in Mexico, Monterrey, investigators found a sensorineural hearing loss frequency of $0.65 / 1,000$ newborns 1 , while in high-risk infants (mainly premature) from a Mexico City-based government-sponsored hospital, investigators reported that the frequency of hearing loss can be as high as $13.4 \%$, mainly related to exposure to ototoxic drugs, hyperbilirubinemia, asphyxia, and low birth-weight 2 . No study on the prevalence of sensorineural hearing loss in children in Mexico has been carried out. However, studies from other Latin-American countries have disclosed important findings. In rural Nicaraguan children, a sensorineural hearing loss prevalence of $18 \%$ was found and was related with middleear infections, family history of deafness, dysmorphism, maternal infection during pregnancy, neonatal distress, low birth-weight and ototoxic drug exposure ${ }^{3}$. In school-aged children from Medellín, Colombia, investigators found a fre- 
quency of $20 \%$ hearing loss in children, and the major associated risk-factors were comprised of: history of language development delay, middleear effusion, deafness in the family, and repetitive acute respiratory infections 4 . In adults in Mexico, hearing loss was estimated to be $21.07 \%$ in 3,726 subjects studied from rural communities; severe and profound hearing loss was found in $6.39 \%$ and $10.31 \%$ respectively 5 . Nonetheless, we observe in the literature that sensorineural hearing loss prevalence and associated risk factors in teenagers have not been studied.

The objective of the present study was to measure the frequency of hearing loss in a sample of teenagers and to weigh its relationship with the teenagers' exposure to several risk factors for sensorineural hearing loss, including respondent history of middle-ear infections, exposure to music at high levels, noise in school workshops or from fireworks, and other noise-producing activities.

\section{Materials and methods}

\section{Subjects}

This study represents part of the work of our research team in investigating the prevalence of hearing and language disorders in Mexico. In this case, the school selected represents a typical public, government-run high-school with students residing within the Mexico City area who are mainly from low- and middle-income families. Inclusion criteria for the study included being a regular high-school student of either gender aged between 14 and 19 years. The protocol was approved by our institution's Ethics and Research Committees.

After scheduled examinations and with the aid of the corresponding school personnel, the randomly chosen students were led to a mobile unit bus for the evaluation: we decided that if a selected student had not attended class on the day of the test, that student would be replaced by the next student of the same gender on the list. Once the students were inside the mobile unit, they were asked to respond to a questionnaire to determine their history with regard to hearing pathologies. Written consent was obtained from the students or from their parents or guardians (if the students were minors) for participation in the study according to the Declaration of Helsinki.

\section{Questionnaire}

We employed a brief questionnaire to assess qualitatively antecedents of several risk factors for sensorineural hearing loss in teenagers. The questionnaire comprises several sections: selfperception of hearing loss; potential ototoxic drugs consumption; antecedent of deafness in the family; recurrent otitis media and head trauma; sport activities performed in noisy environments; noise exposure during leisure time, and noise at high school activities and workshops. If students did not understand the concept in the question, they received a comprehensive explanation prior to their response.

\section{Procedures}

Study personnel were transported daily to the school in a mobile unit bus equipped with audiometric devices and sound-proof chambers. The otoscopic examination was conducted on the teenagers and each canal was cleaned out, where deemed necessary. The throat and nose were also examined. Investigators had extensive experience in the field (at least 10 years of work). Correlations between results from investigators were high (0.92), and any difference in results among examiners was revised and approved by the senior investigator (M.C.M.-W.).

We used a Madsen model Midimate-622 Audiometer (Madsen Electronics, Copenhagen, Denmark) that was calibrated daily according to American National Standards Institute guidelines (ANSI Standard S3.6-2004). Air conduction thresholds were measured for each ear at $0.5,1$ 2, 4, and $8 \mathrm{KHz}$ using the Carhart-Jerger method as described previously 6 . A threshold value was defined as the lowest signal intensity that the child detected monoaurally at least $50 \%$ of the time with a minimum of four trials; stimuli were administered in 5-dB-steps.

Afterwards, a tympanometry was performed to assess the conditions of the tympanic-membrane, middle-ear, and Eustachian-tube function; we employed the AE803 model of Tympanometer (American Electromedics, Hudson USA) with a $225-\mathrm{Hz}$ probe using a conventional clinical methodology 7 .

Cases revealing an inflammatory or infectious process were prescribed medical treatment, but their results were taken into account in the study. All students received information regarding the results obtained and indications concerning preventive measures to avoid noise-induced hearing loss; if these students already presented hearing loss, recommendations were given to avoid its worsening. 


\section{Statistics}

We studied a sample of high school students and calculated sample size with the formula for finite samples, in a population of 1,622 students with an expected frequency of 0.8 , a confidence level of 1.96, and an error of 0.05 . Final sample size was $213.6(\mathrm{~N}=214)$ subjects; their number was adapted proportionally to the previous mentioned gender proportion and to the course semester as shown in Table 1. Calculations were performed using Stats version 2 Software (Deci- sion Analyst Inc., Arlington, USA). The student lists constituted the sampling framework.

Mean \pm standard deviation (SD) of quantitative variables and percentages of binomial variables were calculated. Student $t$ tests and $\chi^{2}$ tests were used to compare quantitative and binomial variables respectively. Strength-of-association among independent variables (sensorineural hearing loss) and risk factors was measured by prevalence ratio and prevalence odds ratio (OR) calculations. The $\mathrm{p}$ value accepted $a$ priori for detecting differences was $\mathrm{p} \leq 0.05^{8}$.

Table 1

Sample proportion by population, gender, and semester in the course.

\begin{tabular}{|c|c|c|c|c|c|c|c|c|}
\hline \multirow[t]{2}{*}{ Semester } & \multicolumn{2}{|c|}{ Female population } & \multicolumn{2}{|c|}{ Female sample } & \multicolumn{2}{|c|}{ Male population } & \multicolumn{2}{|c|}{ Male sample } \\
\hline & $n$ & $\%$ & $\mathrm{n}$ & $\%$ & $\mathbf{n}$ & $\%$ & $\mathrm{n}$ & $\%$ \\
\hline 1st & 28 & 6 & 4 & 6 & 89 & 8 & 12 & 8 \\
\hline $2^{\text {nd }}$ & 135 & 31 & 18 & 31 & 406 & 34 & 53 & 34 \\
\hline $4^{\text {th }}$ & 157 & 35 & 20 & 35 & 362 & 31 & 48 & 31 \\
\hline 6th & 125 & 28 & 16 & 28 & 320 & 27 & 43 & 27 \\
\hline Total & 445 & 100 & 58 & 100 & 1,177 & 100 & 156 & 100 \\
\hline
\end{tabular}

Results

\section{Overall data}

We studied 156 male (73\%), and 58 female (27\%) students $(\mathrm{N}=214)$. Distribution by gender and semester is shown in Table 1. The average subject age was $16.3 \pm 1.07$ years.

\section{Questionnaire}

Adequate, self-reported hearing was reported by $53 \%$ of students; $8 \%$ reported unilateral hearing loss; and $39 \%$ reported that they did not know their hearing status. Aminoglycoside, diuretic, and illegal drug abuse were reported as negative. Other drug consumption was reported by $31 \%$ of the study participants, with alcohol abuse predominating (Table 2). Half of the subjects played a ball sport and only $8 \%$ engaged in other sports, including swimming (Table 2). Recreational noise exposure, mainly to music, was referred to in the following three forms: use of personal stereos; discotheques, and pop-music concert attendance. Sixty-eight subjects (32\%) had exposure to one type of music at a high level, and $21(10 \%)$ were exposed to combined modalities.
Table 2

Questionnaire results in high-school students in the sample.

\begin{tabular}{lc}
\hline & $\%$ \\
\hline Addictions & \\
Alcoholism & 15 \\
Smoking & 6 \\
Both & 10 \\
None & 69 \\
Sports & \\
Ball sports & 42 \\
Swimming & 3 \\
Karate & 5 \\
None & 50 \\
\end{tabular}

Analysis of recreational noise exposure in the three previously mentioned modalities indicates exposure to continuous noise during the past five years on average. Exposure to noise in pop-music concerts and to other forms of exposure to highlevel musical loudness by the same subject had a significant relationship with hearing loss $(\mathrm{p}<$ 0.05). Intensity of recreational noise exposure 
is depicted in Table 3. A significant association was found with attendance at concerts and discotheques $(\mathrm{p}<0.05)$. No association was found with use of personal stereos and sensorineural hearing loss, in spite of the fact that 30 subjects had been using these for more than five years.
Moreover, in addition to exposure to recreational noise in the form of music, students experience unprotected exposure to considerable noise in school workshops; machinery and tool-making workshops were those with the highest attendance levels (13\%).

Table 3

Recreational noise exposure in high-school students of the sample.

\begin{tabular}{lccc}
\hline & $\begin{array}{c}\text { Number of concerts in } \\
\text { the last } 5 \text { years }\end{array}$ & $\begin{array}{c}\text { Discotheque attendance } \\
\text { per month }\end{array}$ & $\begin{array}{c}\text { Number of years using } \\
\text { earphones }\end{array}$ \\
\hline Minimum to maximum & $1-24$ & $1-4$ & $1-10$ \\
Mean ( \pm SD) & $4.2(4.6)$ & $1.85(0.99)$ & $3.4(2.2)$ \\
\hline
\end{tabular}

\section{Audiometric tests}

Otoscopies revealed otoserosis in $10 \%$ of subjects and myringosclerosis in $2 \%$. Tympanometry showed transient abnormal curves: Jerger's types "As" and "Ad" were found in $10 \%$ and $8 \%$ of subjects, respectively, but only $2 \%$ presented permanent conductive hearing loss (Jerger's type "C"). Hearing loss was found in $21 \%$ of students. 39 subjects showed a mild noise-related sensorineural hearing loss, and five exhibited moderate noise-related hearing loss (Table 4) with bilateral affection in 23 and unilateral in 21 subjects. The right ear was slightly more affected than the left.

\section{Association between questionnaire and audiometric data}

The degree of hearing loss related to a musicalorigin and recreational noise exposure was more frequent in those attending concerts and using personal stereos for both genders; eight cases were not related with this type of exposure. Of the 67 ears with noise-related sensorineural hearing loss, 48 were not involved in noisy school workshops and only 13 were exposed to machinery and tools workshop. In seven of the 31 students, the cause of noise exposure could not be determined. We measured strength-of-association between hearing-loss risk factors and acoustic trauma. A moderate association was obtained with four factors, and the highest value was found for pop-music concert attendance and for combined exposure to recreational noise. OR with values $>2$ was found for three variables; exposure to a noisy
Table 4

Audiometric results in high-school students in the sample.

\begin{tabular}{lcc}
\hline Test & Normal (\%) & Abnormal (\%) \\
\hline Otoscopy & 88 & 12 \\
Tympanometry & 80 & 20 \\
Audiometry & 79 & 21 \\
\hline
\end{tabular}

school workshop was an outlier. A significant relationship was found for all three recreationalnoise exposure modalities and for noise exposure in school workshops (Table 5).

\section{Discussion}

\section{Main findings and overall data}

The main finding of this study was the existence of a high frequency of sensorineural hearing loss among teenagers from low- and middle socioeconomic strata at a typical high school in Mexico City when compared with data from other studies performed in developed countries such as the U.S. 12.5 vs. $20 \%$ 9. However, this high frequency is in agreement with data after the AbdelRahman et al. 10 study, whose authors report a prevalence of $22 \%$ in a sample of adolescents in another developing country: Egypt. The hearing loss that we found was mainly related to noisy recreational activities, a fact that is a well-recognized risk factor for sensorineural hearing loss 11 . 
Association measures of risk factors with hearing loss.

\begin{tabular}{|c|c|c|c|c|c|c|}
\hline Risk factor & PR & $95 \% \mathrm{Cl}$ & $\begin{array}{l}\text { Association } \\
\text { power }\end{array}$ & OR prevalence & $\chi^{2}$ & $p$ value \\
\hline Gender & 1.5 & $0.32-1.91$ & Weak & 1.5 & 1.951 & \\
\hline Addiction & 0.72 & $0.31-1.48$ & None & 0.67 & 0.696 & \\
\hline Unprotected sports & 1.60 & $0.73-2.69$ & Moderate & 1.9 & 3.193 & \\
\hline Earphone use & 0.80 & $0.47-1.29$ & None & 0.75 & 0.461 & \\
\hline Concert attendance & 1.92 & $1.13-3.22$ & Moderate & 2.2 & 5.651 & $<0.05$ \\
\hline Discotheque attendance & 1.38 & $0.81-2.31$ & Weak & 1.46 & 1.152 & \\
\hline Earphones and concerts & 1.5 & $1.07-2.93$ & Weak & 1.74 & 2.299 & \\
\hline Earphones and discotheques & 0.76 & $0.34-1.66$ & No association & 0.70 & 0.775 & \\
\hline Concerts and discotheques & 1.77 & $0.99-3.15$ & Moderate & 2.08 & 3.831 & $<0.05$ \\
\hline Earphones, discotheques and concerts & 1.42 & $0.69-2.91$ & Weak & 1.50 & 6.818 & $<0.05$ \\
\hline School workshops & 2 & $1.07-3.34$ & Moderate & 2.43 & 4.830 & $<0.05$ \\
\hline Fireworks & 1.4 & $0.78-2.31$ & Weak & 1.30 & 1.058 & \\
\hline
\end{tabular}

95\% Cl: 95\% confidence intervals; OR: odds ratio; PR: prevalence ratio.

The sample used was proportional to gender and semester in course, and subjects' ages correspond with those of teenagers. Bilateral presentation of sensorineural hearing loss in 23 cases confirms exposure to intense and continuous noise.

The commercial music industry and technological development have in part led to an increasing number of teenagers participating in leisure-time activities that involve exposure to music at high intensity. The most frequent reported recreational activities among teenagers from our sample correspond to attendance at concerts and discotheques, as well as combining such an activity with the use of a personal stereo, which among other alterations produce changes in the Corti's organ 12,13,14,15,16,17,18,19,20,21,22,23,24. Although $75-80 \%$ of adolescents in Mexico are aware of the secondary effects of this noise exposure, they continue to place themselves indiscriminately in situations of exposure.

Music at high intensity levels can be considered as continuous and unstable sound that may induce transient temporary hearing loss with temporal manifestations that can last minutes, hours, or days after the cessation of the intense stimulus, or that can be permanent due to repetitive exposure to noise ${ }^{9}$. Sound pressure levels in the ear become damaging at $>75 \mathrm{~dB}(\mathrm{~A})$ and painful at $120 \mathrm{~dB}(\mathrm{~A})$; the tolerance limit recommended by the World Health Organization (WHO) is $75 \mathrm{~dB}$ (A) 25 . The ear requires more than 16 hours of rest to compensate for 2 hours of exposure at $100 \mathrm{~dB}(\mathrm{~A})$ after attendance at concerts and discotheques. Noises that are greater than $120 \mathrm{~dB}(\mathrm{~A})$, such as those produced by several pop-music groups or those from personal stereos played at a loud volume can result in permanent hearing loss, with a single exposure in some cases. Impact noise at levels $>140 \mathrm{~dB}$ (A), such as that produced by drums in bands, can induce immediate hearing loss.

Risk factors for noise-induced hearing loss in teenagers mainly comprise the following: time of exposure and noise intensity [in workers, exposure to $>90 \mathrm{~dB}$ (A) during eight working hours for five or more years]; age and recreational sound activities, depending on age at beginning of exposure to noise, noise duration, noise intensity, and the frequency at which exposure occurs; inherited genetic factors regarding ear sensitivity to noise, and otologic antecedents. Risk is higher in ears with previous pathology. With regard to gender, women maintain better hearing, and characteristics of the environment including direct protection barriers such as the use of ear-plugs, and room conditions. Hearing loss progression and continuous exposure to noise could lead the teenagers of today to troubles with language comprehension, academic failures, and the use of hearing aids at an average age of 50 which is 20 years earlier than their parents would have had to do the same.

\section{Questionnaire}

Questionnaires represent a useful tool for screening many harmful diseases, including hearing loss in adolescents; moreover, a recent web-based 
survey was performed with excellent results 26 . Regarding certain hearing loss-associated risk factors, the sample of teenagers studied comprised a special group at risk of sensorineural hearing loss in terms of age. Calculating the association with the pathology revealed that there is a 1.5-times higher probability of suffering a hearing loss among men.

Certain sports activities require direct ear protection, such as swimming 27 , mountain climbing, boxing, motorcycling, firearms use, and others, as investigated in adolescent and young workers 28 . In our study, sports showed no significant association; this may be explained because the favorite game of teenagers in Mexico were ball games such as soccer and basketball, sports in which high-level noise-exposure is notsignificant.

Exposure to recreational noise presented a powerful association with sensorineural hearing loss, that is, $>1$ for all modalities, except in the case of the use of personal stereos alone and in use of earphones with attendance at discotheques. Exposure to noise in pop-music concerts and to the three modalities of high-level loudness exposure in music by the same subject had a significant relationship that has been reported in the medical literature $12,13,14,15,16,17,18,19,20,21,22,23,24$. No association was found with the use of personal stereos alone, despite the fact that 30 subjects have been using these for more than five years, but a significant association was found with noise exposure in concerts and discotheques alone or in a combined fashion (including use of personal stereos). If we consider that the maximal permissible limits of noise exposure, which indicate no more than eight hours at $90 \mathrm{~dB}$, no more than four hours at $93 \mathrm{~dB}(\mathrm{~A})$, and no more than 15 minutes at $105 \mathrm{~dB}(\mathrm{~A})$, our data suggest that youngsters in Mexico may exceed these limits in both time and intensity. Moreover, we must take into account the exposure of teenagers to other noise sources, such as noisy school workshops and fireworks explosions, the first of which showed a significant correlation.

\section{Audiometric findings}

A history of pathological ear problems was established by means of otoscopy and tympanometry, even when denied by some students, but did not reveal a significant association with sensorineural hearing loss. More recently, novel methods to assess hearing loss as a result of noise exposure are being employed, such as otoacoustic emissions that can predict lesions prior to their being disclosed by a clinical audiometry, and these are used more frequently to assess exposure to work- related noise 29 . Studies concerned with exposure to urban recreational or environmental noise are scarce in Mexico, but one study found high levels of street noise during day time, related to automotive traffic ${ }^{30}$. Additional research is difficult to perform due to the lack of resources allotted to this risk group; but teenagers total around 8 million of the population of Mexico, and $60 \%$ are high-school students, so further research is necessary.

There is controversy among researchers regarding the issue of personal stereo use among adolescents; there are those who consider that there is no greater susceptibility to hearing loss in teenagers with a case history of otitis media 31 , whereas others have found there to be significant hearing loss among those with an otitis media history ${ }^{32}$. To search for these antecedents requires the prospective use of otoscopies and tympanometries in personal stereo users to determine alterations in middle ear integrity and function. We must perform larger prospective studies to confirm results from the data of this study, due to the small size and geographic limitations of our sample.

An important factor that may impair hearing perception in teenagers with sensorineural hearing loss is high levels of noise in classrooms. For example, the average noise levels measured in different elementary school rooms in Japan were found to be around $50 \mathrm{~dB}(\mathrm{~A})$, teachers' speech levels averaged $60 \mathrm{~dB}(\mathrm{~A})$, and there was a mean speech-to-noise ratio of $11 \mathrm{~dB}(\mathrm{~A})$ during teaching activities. Mean reverberation time in occupied classrooms was 0.41 seconds 33 . The presence of a high background noise may be the most dangerous factor that impairs discrimination of language sounds in Mexican teenagers with sensorineural hearing loss. We propose that these factors can act alone or in a combined manner to impair cognitive abilities, which depend mainly on hearing in young individuals with sensorineural hearing loss.

\section{Hearing loss as a public health concern}

Public health concerns about noise-induced hearing loss are growing. Several recent studies have shown that sensorineural hearing loss is the most frequently occurring preventable disability and that it can be caused by recreational or occupational sources 34,35. Nearly 22 million Americans between 20 and 69 years of age have suffered irreversible damage. However, no data about sensorineural hearing loss prevalence at these ages in Mexican studies are available. Studies carried-out on the use of hearing protection have demonstrated an increase in hearing trouble for 
children at ever younger ages 36 , suggesting that many sources of noise may already be impacting the hearing of young people. Individuals suffering from sensorineural hearing loss often exhibit reduced psychosocial functions and, increased feelings of isolation, depression, loneliness, anger, fear, frustration, and disappointment in their most productive years of life. These facts must be changed in order to develop hearing conservation programs in teenagers, educating participants on the dangers of exposure to high-noise levels and on ways to protecting their auditory system. Unfortunately, there remains a paucity of educative and health authorities in Mexico for the development of programs of hearing health conservation. Moreover, Mexican teenagers have negative attitudes toward the use of measures of hearing protectors such as ear-plugs, and toward avoiding high levels of music in their leisure time. Thus, data from this study may contribute to alerting both teenagers and authorities to take preventive measures against sensorineural hearing loss in teenagers.

Our study has some limitations. We performed a cross-sectional study instead of a prospective follow-up with a more statistical power. The sample size is small, thus in future studies our team must utilize larger samples in more schools in the Mexico City area. This action can be attained with the combined work of different research teams. The lack of certain associations will be related with low statistical power.

\section{Conclusions}

The frequency of hearing loss in high school students from Mexico City exposed to noise may be high at one fifth of the studied sample. These data merit concern on the part of Health Department authorities, because they reveal that hearing loss in teenagers is a major public health concern in Mexico City.

Sensorineural hearing loss in teenagers was significantly related to noisy recreational activities. These data must be taken into account in planning strategies for sensorineural hearing loss prevention, such as specific education in hearing conservation, mandatory limits of the sound intensity of personal stereos, and of loudness in discotheques and pop-music concerts, and the use of ear plugs for protecting hearing in loud environments.

\section{Resumen}

El objetivo de este estudio fue medir la frecuencia de alteraciones auditivas en una muestra de escolares de educación media superior expuestos a ruido recreativo y determinar algunos factores de riesgo asociados. La muestra estuvo constituida por 214 adolescentes de una escuela de la Ciudad de México. Los sujetos fueron seleccionados al azar por medio de una computadora. Se aplicaron cuestionarios con el objeto de identificar los factores de riesgo para alteraciones auditivas y se les practicaron diversos estudios audiológicos consistentes en: otoscopía, timpanometría y una audiometría a tonos puros. La edad media de la muestra fue de $16 \pm 1,07$ años, $73 \%$ fueron del sexo masculino y $27 \%$ femenino. Se encontraron alteraciones auditivas en $21 \%$ de los estudiantes. Los principales factores de riesgo asociados a alteraciones auditivas fueron: exposición al ruido recreativo al asistir a discotecas, conciertos de música popular, el uso de equipos de sonido personales y la exposición al ruido en los talleres escolares. Se halló una alta frecuencia (casi una quinta parte) de alteraciones auditivas en alumnos de educación media superior asociada a la presencia de ruido recreativo excesivo.

Pérdida Auditiva; Efectos del Ruido; Trauma Acústico; Adolescente 


\section{Contributors}

M. C. Martínez-Wbaldo designed the study, studied patients, process results and wrote the manuscript. C. Soto-Vázquez, I. Ferre-Calacich, E. Zambrano-Sánchez, L. Noguéz-Trejo studied patients, process results and wrote the manuscript. A. Poblano designed the study, was responsible for statistical analysis and wrote the manuscript.

\section{Acknowledgments}

We thank the authorities and teaching personnel at the high school, particularly the principal Prof. M. D. Labastida for her support in performing the study, and Mrs M. Brunner, M.A., for her help in the preparation of the English version of the manuscript.

\section{References}

1. Yee-Arellano HM, Leal-Garza F, Pauli-Müller J. Universal newborn hearing screening in Mexico: Results of the first 2 years. Int J Pediat Otorhinolaryngol 2006; 70:1863-70.

2. Garza Morales S, Poblano A, Robledo Galván A, Fernández Carrocera LA. Auditory evoked potentials in children at neonatal risk for hypoacusis. Rev Panam Salud Pública; 2:232-7.

3. Saunders JE, Vaz S, Greinwald JH, Lai J, Morin L, Mojica K. Prevalence and etiology of hearing loss in rural Nicaraguan children. Laryngoscope 2007; 117:387-98.

4. Rodríguez GMA, Melguizo-Yepez M. Screening for hearing disorders in school children of Medellín, Colombia, 1993. Salud Pública Méx 1994; 36:670-2.

5. Montes de Oca Fernandéz E, Rodríguez Díaz JA, Arias Aranda JI, Chavira Contreras CL. Morbilidad de los defectos auditivos en comunidades rurales de ocho estados de la República Mexicana. An Otorrinolaringol Mex 1993; 38:3-9.

6. Escalante-Ugalde C, Poblano A, Montes de Oca Fernandéz E, Lagunes R, Saúl A. No evidence of hearing loss in patients with vitiligo. Arch Dermatol 1991; 127:1240.

7. Shanks J, Shelton C. Basic principles and clinical applications of tympanometry. Otolaryngol Clin North Am 1991; 24:299-328.
8. Dawson-Saunders B, Trapp RG. Bioestadística médica. México DF: Manual Moderno; 1997.

9. Niskar AS, Kieszack SM, Holmes AE, Esteban C, Rubin E, Brody DJ. Estimated prevalence of noiseinduced hearing threshold shifts among children 6 to 19 years of age: Third National Health and Nutrition Examination Survey, 1988-1994, United States. Pediatrics 2001; 108:40-3.

10. Abdel-Rahman AG, Meky FA, Allam MF, El-Tabakh M, El-Gaafay MM. Prevalence and risk factors for hearing disorders in secondary school students in Ismailia, Egypt. East Mediterr Health J 2007; 13:586-94.

11. Vogel I, Brug J, van der Ploeg CP, Raat H. Young people's exposure to loud music: a summary of the literature. Am J Prev Med 2007; 33:124-33.

12. Lebo CP, Oliphant KS, Garret J. Acoustic trauma from rock-and-roll music. Calif Med 1967; 107: 378-80.

13. Reddell RC, Lebo CP. Ototraumatic effects of hard rock music. Calif Med 1972; 116:1-4.

14. Axelsson A, Jerson T, Lindgrenn F. Noisy leisure time activities in teenage boys. Am Ind Hyg Assoc J 1981; 42:229-33.

15. Hartman BT. An exploratory study of the effects of disco music on the auditory and vestibular systems. J Aud Res 1982; 22:271-4. 
16. Carter NL, Waugh RL, Keen K, Murray N, Bulteau BG. Amplified music and young people's hearing. Review and report of Australian findings. Med J Aust 1982; 2:125-8.

17. Meyer-Bisch C. Epidemiological evaluation of hearing damage related to strongly amplified music (personal cassette player, discotheques, rock concerts): high definition audiometric survey on 1364 subjects. Audiology 1996; 35:121-42.

18. Becher S, Struwe F, Schwenzer C, Weber K. Risk of hearing loss caused by high volume music: presenting an educational concept for preventing hearing loss in adolescents. Gesundheitswesen 1996; 58:91-5.

19. Ising H, Babisch W, Hanee J, Kruppa B. Loud music and hearing risk. Journal of Audiological Medicine 1997; 6:123-33.

20. Jokitulppo JS. Bjork EA, Akaan-Penttila E. Estimated leisure noise exposure and hearing symptoms in Finnish teenagers. Scand Audiol 1997; 26 257-62.

21. Dalton DS, Cruickshanks KJ, Wiley TI, Klein BE, Klein R, Tweed TS. Association of leisure time noise exposure and hearing loss. Audiology 2001; 40:1-9.

22. Sahra S, Jackson CA, Ryder T, Brown MJ. Noise exposure and hearing loss among student employees working in university entertainment venues. Ann Occup Hyg 2002; 46:455-63.

23. Fligor BJ, Cox LC. Output levels of commercially available portable compact disc players and the potential risk to hearing. Ear Hear 2002; 25:513-27.

24. Warwick W. Personal stereo noise exposure. Int J Audiol 2005; 44:231-6.

25. Smith AW. The World Health Organization and the prevention of deafness and hearing impairment caused by noise. Noise Health 1998; 1:6-12.

26. Chung, JH, Roches CM, Meunier J, Eavey R. Evaluation of noise-induced hearing loss in young people using a web-based survey technique. Pediatrics 2005; 115:861-7.
27. Wang MC, Liu CY, Shiao AS, Wang T. Ear problems in swimmers. J Chin Med Assoc 2005; 68:347-52.

28. Neitzel R, Seixas N, Goldman B, Daniell W. Contributions of non-occupational activities to total noise exposure of construction workers. Ann Occup Hyg 2004; 48:463-73.

29. ShupakA, Tal D, Sharoni Z, Oren M, Ravid A, Pratt H. Otoacoustic emissions in early noise-induced hearing loss. Otol Neurotol 2007; 28:745-52.

30. Poblano A, Arch Tirado E, Morales Martínez JJ, Arias Aranda I, Montes de Oca Fernández E. Niveles de contaminación por ruido en una de las principales avenidas de la ciudad de México. An Otorrinolaringol Mex 1995; 40:63-7.

31. Beer BA, Graamans K, Snik AF, Ingels K, Zielhuis GA. Hearing deficits in young adults who had a history of otitis media in childhood: use of personal stereos had no effect on hearing. Pediatrics 2003; 111:304-8.

32. Job A, Raynal M, Rondet P. Hearing loss and use of personal stereos in young adults with antecedents of otitis media. Lancet 1999; 353:35.

33. Sato H, Bradley JS. Evaluation of acoustical conditions for speech communication in working elementary school classrooms. J Acoust Soc Am 2008; 123:2064-77.

34. Rosenhall U, Pyykkö I, Rasmussen F, Muhr P. Hearing loss in young men: possible aetiological factors. Noise Health 2006; 8:40-4.

35. Shah S, Gopal B, Reis J, Novak M. Hear today, gone tomorrow: an assessment of portable entertainment player use and hearing acuity in a community sample. J Am Board Fam Med 2009; 22:17-23.

36. Crandell C, Mills TL, Gauthier R. Knowledge, behaviors, and attitudes about hearing loss and hearing protection among racial/ethnically diverse young adults. J Natl Med Assoc 2004; 96:176-84.

Submitted on $07 / \mathrm{Jul} / 2008$

Final version resubmitted on 16/Jun/2009

Approved on 03/Sep/2009 